\title{
Postgraduate Symposium
}

\section{Exercise for optimising peak bone mass in women}

\author{
C. A. Bailey and K. Brooke-Wavell* \\ Department of Human Sciences, Loughborough University, Leics. LE11 3TU, UK
}

\begin{abstract}
Physical activity is one of the major non-pharmacological methods for increasing and maintaining bone mineral density (BMD) and geometry. As such, it has an important role in maintaining peak bone mass and strength, thus reducing the risk of future osteoporotic fracture. However, not all exercise is effective, so a prescription in terms of optimal type, intensity, frequency and duration is required. Studies using animal models suggest that loading that is high in magnitude, rapidly applied and novel is most effective, whilst duration is less important beyond a threshold number of cycles. In human subjects cross-sectional studies comparing different athletic populations suggest that those who participate in high- or odd-impact sports have higher BMD; whilst impact exercise, strength training and brief high-impact-jump training interventions increase BMD in premenopausal women. In order to further elucidate exercise recommendations to optimise bone health in this population, the usefulness of brief high-impact unilateral exercises has been evaluated. Brief hopping exercises were shown to be feasible for sedentary premenopausal women, producing ground-reaction forces as high as those from jumping. Regularly performing these hopping exercises over 6 months was found to increase femoral-neck BMD of the trained leg relative to the control leg. Unilateral high-impact exercise may therefore improve bone strength of the trained limb and provide a useful model for comparing exercise prescriptions to help define the most efficient and effective exercise recommendations for the bone health of premenopausal women.
\end{abstract}

\section{Exercise: Bone mineral density: Premenopausal women}

Osteoporosis is a condition of skeletal fragility whereby depleted bone mass and compromised bone structure weaken bone to such an extent that fractures occur from minimal trauma. The disease is a major public health problem with great social and economic importance. One in five men and one in two women in the UK $>50$ years of age will suffer an osteoporosis-related fracture in their lifetime ${ }^{(1)}$ and the annual cost for all fractures is $£ 1.5 \times 10^{9(2)}$.

Two mechanisms that principally determine adult bone health are peak bone mineral density (BMD) at skeletal maturity and the rate of bone loss with advancing age; thus, maximising premenopausal BMD is a critical strategy for the prevention of osteoporosis and resultant fractures later in life. A substantial body of literature has established that participating in regular physical activity can positively improve bone mineral status ${ }^{(3,4)}$. The advantage of exercise over methods such as dietary intervention is that it increases the skeleton's resistance to fracture by improving and maintaining both BMD and neuromuscular competency, thus reducing both skeletal fragility and predisposition to falls ${ }^{(4)}$.

Exercise recommendations for cardiovascular fitness have already been precisely defined ${ }^{(5)}$, but it is unlikely that the same exercise prescription applies to cardiovascular health and skeletal health, and to both pre- and post-menopausal women. Bone's response to exercise differs across the lifespan according to the age and health of the individual ${ }^{(6)}$, yet in the past research has focused predominantly on post-menopausal women and studies involving premenopausal women are sparser.

The aim of the present review is to describe what is known about exercise as an intervention to increase BMD among premenopausal women and, learning from past 


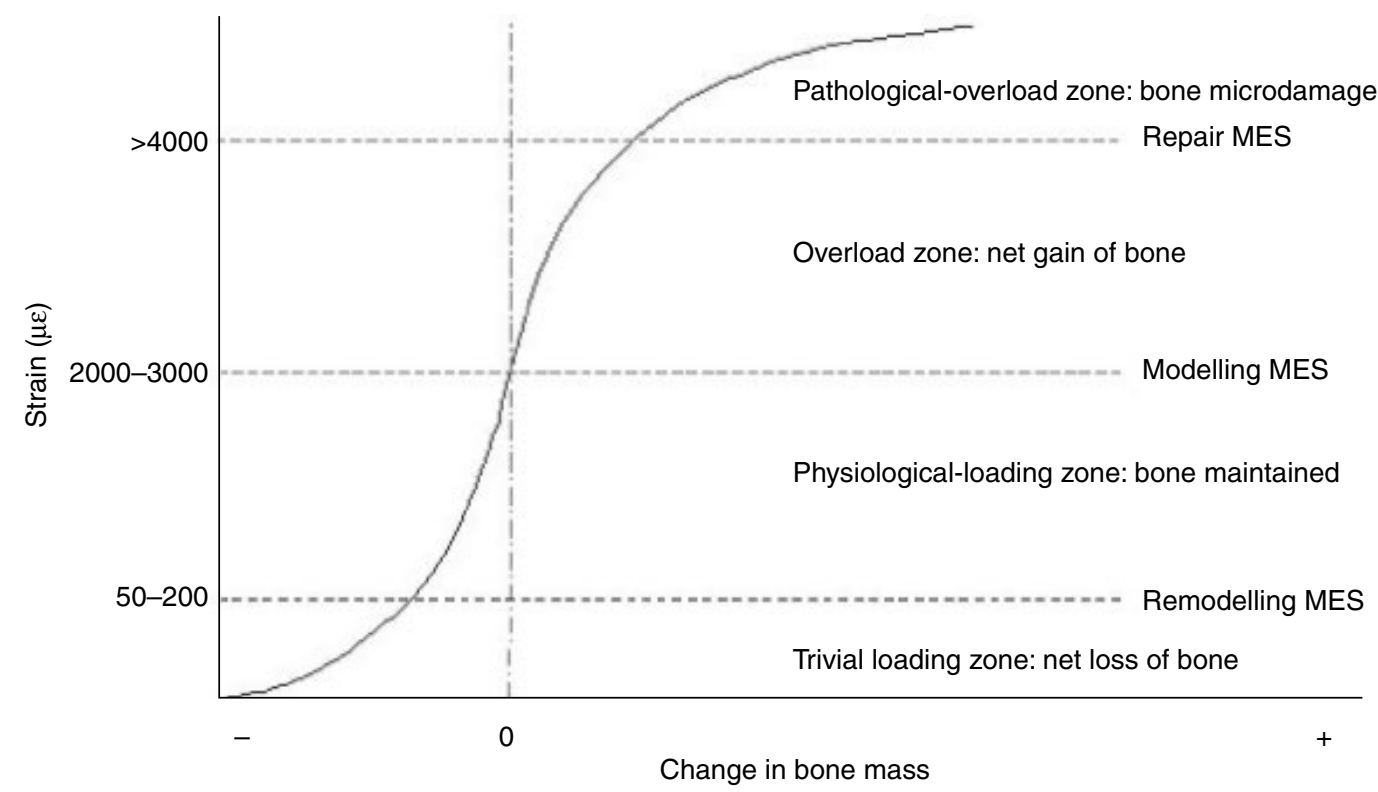

Fig. 1. Diagrammatic representation of predicted change in bone mass relative to applied strain according to the mechanostat theory. MES, minimum effective strain; -, loss; +, gain. (Adapted from Frost ${ }^{(7)}$.)

studies, how future interventions could potentially fill the gaps in current knowledge.

\section{Determinants of bone strength}

There is a dynamic regulatory system in bone that adapts its strength to its mechanical environment by alterations in the amount and orientation of bone at each skeletal site. This adaptation process is described as Wolff's Law after the German scientist who first recognised in 1892 how 'every change in environment is followed by change in internal architecture', and how there is a mechanism for functional adaptation in the skeleton. Since then, the principle has further developed into the mechanostat theory ${ }^{(7)}$, which describes the mechanism of bone adaptation like a thermostat (Fig. 1). Bone has various set points of minimum effective strain (MES) that are independently and interdependently determined by local (e.g. previous load-bearing), systemic (e.g. hormones) and external (e.g. diet) factors, as well as age and genetics ${ }^{(8)}$. If mechanical loading increases and exceeds the relative MES (i.e. what bone is accustomed to), bone formation:bone resorption is temporarily unbalanced until mineral mass increases and structural adaptation occurs so that bone becomes strong enough to support the greater functional demands being placed on it. A new MES is then established. Conversely, if loading on bone decreases and falls below the MES threshold there is a rapid loss of BMD, because a lessdemanding external environment allows the metabolic cost of maintaining mineral to be reduced ${ }^{(9)}$. This loss is substantial, as decreases in BMD of approximately $1 \% /$ month have been reported during times of immobilisation or bed rest $^{(10)}$ and weightlessness ${ }^{(11)}$, compared with the average loss of $<1 \% / y e a r$ normally observed in older postmenopausal women.
The mechanical competence of bone is a function not only of its intrinsic material properties (mass, density and stiffness), but also of its structural properties (size, shape and geometry). Dual-energy X-ray absorptiometry is the method most commonly used to measure areal BMD $\left(\mathrm{g} / \mathrm{cm}^{2}\right)$ and bone mineral content $(\mathrm{g})$ because of its speed, precision, low radiation exposure and availability of reference data ${ }^{(12)}$. However, the understanding of bone's response to mechanical loading is restricted by these two-dimensional skeletal outcomes that represent only one part of overall bone strength. The development of hip structural analysis algorithms has enabled estimation from dual-energy X-ray absorptiometric scans of certain bone structural changes that may occur along with bone densitometric changes to further increase bone strength ${ }^{(13,14)}$. Studies have shown that exercise can positively alter structural variables, sometimes in the absence of detectable changes in $\operatorname{BMD}^{(15,16)}$.

\section{Animal studies}

Studies using animal models have established the characteristics of mechanical loading for optimal bone formation. First, it is clear that strain from mechanical loading needs to be of a high magnitude. As explained previously by the mechanostat theory, strain needs to exceed the set MES, which is usually about 2000-3000 microstrain. After this point and until the upper MES threshold, at which excessive loading causes damage to bone, there is a graded dose-response relationship between the peak strain magnitude and the change in the mass of bone tissue present ${ }^{(17,18)}$. Second, a high rate of strain provides a greater osteogenic stimulus than the same peak strain achieved more slowly. Rat ulnae subjected to high-strainrate $(0 \cdot 1 \mu \varepsilon / \mathrm{s})$ in vivo loading have been demonstrated to 
have a $54 \%$ greater osteogenic response than a moderatestrain-rate group $(0.03 \mu \varepsilon / \mathrm{s})$, who in turn show a $13 \%$ larger response than a low-strain-rate group $(0 \cdot 018 \mu \varepsilon / s)^{(19)}$. Third, bone adaptation is driven by unusual strain distributions. The 'error strain distribution hypothesis'(9) proposes that bone cells enhance the skeleton's structural competence by adjusting to perceived deviations from normal in the distribution of dynamic strains. For example, strain produced by loading in torsion may be less osteogenic than the same strain produced by loading in longitudinal compression. Furthermore, it has been suggested that the distribution of strain may be more important than its magnitude ${ }^{(20)}$, as unusual patterns of strain can stimulate an osteogenic response at a lower MES ${ }^{(17)}$. Fourth, the number of cycles of loading applied to bones appears to become unimportant once a certain threshold level has been reached ${ }^{(18)}$. As few as thirty-six loading cycles lasting only $72 \mathrm{~s}$ have been shown to stimulate maximal bone formation in turkey ulnae ${ }^{(17)}$ and 100 jumps per d produce the same bone response in rats as forty jumps per $\mathrm{d}^{(21)}$. Likewise, it has been found that the rate of bone formation in avian ulnae when compared with that of contralateral bones is not significantly elevated by five consecutive days of 100 low-magnitude-loading cycles, but is elevated by separating the 100 cycles into ten bouts with $10 \mathrm{~s}$ rest between bouts ${ }^{(2)}$. Thus, prolonged periods of mechanical loading saturate the bone's adaptive response to mechanical load. Following from this finding, it has been demonstrated that inserting regular rest periods between loading bouts maintains the mechanosensitivity of bone, whereas static load applied continuously produces no effect different from disuse ${ }^{(23)}$. In rats allowed time to recover between thirty-six identical daily loading cycles, $14 \mathrm{~s}$ of recovery resulted in significantly higher (66-190\%) relative bone formation rates when compared with three shorter recovery periods $(0.5,3.5$ and $7 \mathrm{~s})$; furthermore, in the longer term, $4 \mathrm{~h}$ rest doubles bone formation whilst a further $4 \mathrm{~h}$ of recovery restores full mechanosensitivity to desensitised bone cells ${ }^{(24)}$. Thus, mechanical loading is not only more osteogenic when short rest intervals are inserted between cycles, but also when each bout of loading is separated by several hours. However, the optimum frequency of loading bouts, i.e. the number of times per week that is required for maximising bone accrual, has not yet been established.

Finally, animal studies have demonstrated that bone has an age-dependent response to mechanical loading and the importance of oestrogen for bone's adaptation to be fully realised has been highlighted. Following an 8-week period of unilateral daily loading of a physiologically-normal level of strain, bone cross-sectional area in 1-year-old turkey ulnae has been found to increase by $30 \cdot 2 \%$ as compared with their intact contralateral control ulnae, whereas the areal properties of the 3-year-old turkeys remain essentially unchanged $(-3 \cdot 3 \%)^{(25)}$. The authors have suggested that a physical signal that is clearly osteogenic in the young adult skeleton is scarcely acknowledged in older bone tissue. Whether this difference in response represents a deterioration of the ability of older bone cells to perceive these physical signals or a failure of their capacity to respond is not yet clear. It may also be linked to the role of oestrogen in amplifying the osteogenic response to a single period of loading, because in animal models of post-menopausal osteoporosis exercise prevents early bone loss after ovariectomy but does not actually stimulate bone formation ${ }^{(26,27)}$.

The advantage of animal studies is that they can be very tightly controlled and in vivo adaptation of bone mineral content and strength can be assessed, although it cannot be confirmed that human bone responds in exactly the same way as animal bone since invasive procedures cannot be carried out on human subjects. Consequently, clarification of the effects of mechanical loading on bone in human subjects relies on cross-sectional observations of different human populations and longitudinal intervention studies.

\section{Cross-sectional studies}

Evidence for the importance of mechanical loading comes from numerous studies that have compared the BMD values of individuals who take part in different types of sports. Differences in BMD have consistently been shown between athletes participating in sports involving high ground-reaction forces (GRF) and those participating in low- or no-impact sports ${ }^{(28-30)}$. The largest differences have regularly been observed in gymnasts whose hip and spine BMD values are 30-40\% higher than those of longdistance runners ${ }^{(31)}$; a plausible explanation being the greater magnitude of impact forces generated in gymnastics movements $(10-12 \times \text { body weight })^{(32)}$ compared with running $(3-5 \times \text { body weight })^{(33)}$. Moreover, not only are high-impact sports associated with a greater BMD, but also athletes involved in high-impact sports have a greater section modulus (a predictor of strength in bending) (29) $^{(29}$ (Fig. 2). On the other hand, the bone properties of swimmers, who do not experience any loading, are no different from those of sedentary controls ${ }^{(28)}$.

Related to the concept of strain distribution, sports such as squash, volleyball and gymnastics, which stress bone in a variety of directions, are associated with a higher BMD than sports consisting of only one direction of movement, e.g. running ${ }^{(28)}$. Similarly, zig-zag hopping produces higher compression, tension and shear strains than those of jogging and walking, and hence it has been proposed that this kind of activity may be an optimal tibial bonestrengthening exercise ${ }^{(34)}$. The low BMD reported amongst long-distance runners ${ }^{(35)}$ supports the finding from animal studies that bone adapts to the current loading magnitude and that increasing the duration of loading above the established MES confers no additional benefit, although the low BMD may be exacerbated by the common occurrence of menstrual irregularities (i.e. oestrogen deficiency) in this particular population ${ }^{(36)}$. Other human studies support the greater importance of loading magnitude compared with its duration. For example, it has been reported that $>100$ accelerations per $d$ are positively associated with higher BMD providing they exceed $3.9 \mathrm{~g}^{(37)}$. Thus, it is likely that human bone would also become less desensitised to loading if regular rest intervals intersperse loading cycles; yet, as with animal studies, the response of human bone to varying weekly 


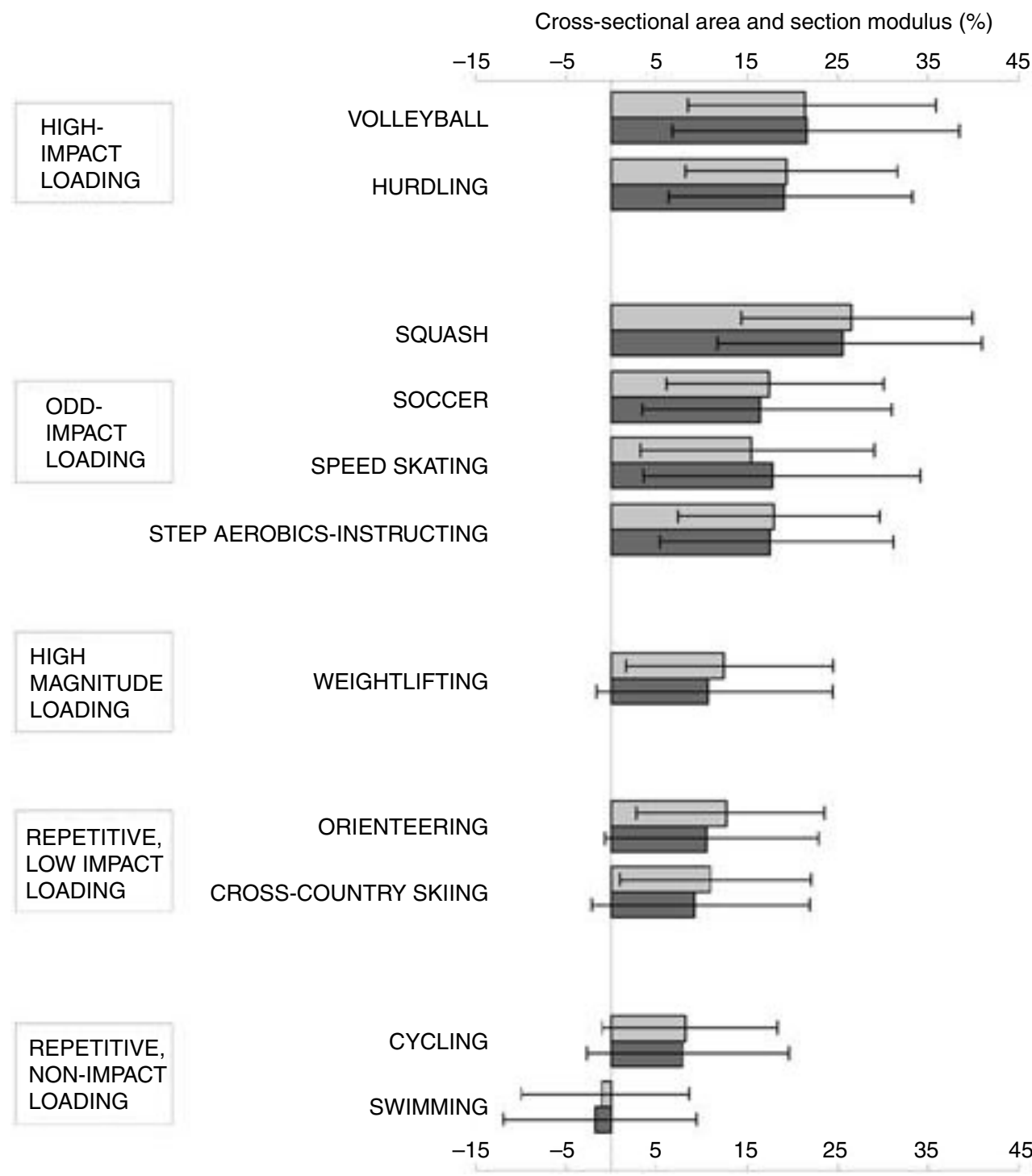

Fig. 2. Differences in cross-sectional area $(\square)$ and section modulus (a predictor of strength in bending; $\square$ ) between athletes participating in sports of different loading modalities and controls. Values are means and $95 \% \mathrm{Cl}$ represented by horizontal bars. Where the $95 \% \mathrm{Cl}$ does not cross the zero line (the value for the controls) the difference was significant $(P<0 \cdot 05)$. (From Nikander et al. ${ }^{(29)}$ Reproduced from $J$ Bone Miner Res (2005) 20, 520-528 with permission of the American Society for Bone and Mineral Research.)

frequencies of loading has not been defined. Along with the type, duration and intensity, frequency of exercise is an important aspect of exercise prescription and warrants investigation.

\section{Cross-sectional unilateral studies}

The major limitation of cross-sectional studies is selfselection bias, i.e. individuals with a higher BMD may be more predisposed to participate in sports and exercise. Their diets and other lifestyle habits may contribute to their success in maintaining a high BMD and it is likely that they have been participating in regular physical activity since childhood. Indeed, such long-term exercisers seem to have greater BMD than those who started exercising in adulthood ${ }^{(38)}$. Cross-sectional studies that compare the limbs within the same individual reduce the confounding effect of selection bias. Significant differences in bone density and structure between the dominant and non-dominant limb are attributed to lifetime loading of the favoured dominant side ${ }^{(39,40)}$. The effect of loading is even more marked when comparing the arms of racquet-sport players. The difference in bone mineral between tennis players' playing arm and non-playing arm has been estimated to be $13 \%{ }^{(41)}$. The age-related response to loading is also apparent in such studies, as the side-to-side differences in BMD that have been noted in pubescent players compared with age-matched controls are not manifested until the girls reached Tanner Stage III, which is the age associated with the adolescent growth spurt ${ }^{(42)}$. In contrast, players who start playing after 30 years of 


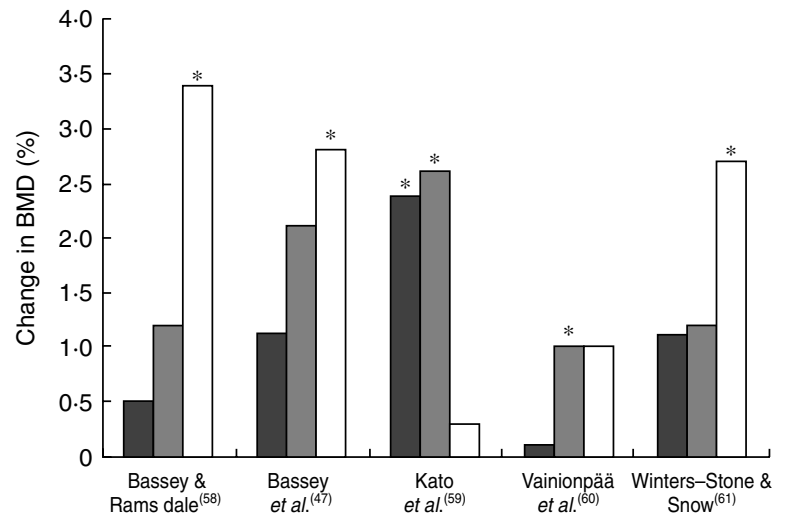

Fig. 3. Summary of bone mineral density (BMD) changes observed in randomised controlled intervention trials involving high-impact exercise in premenopausal women. ( $\square$ ), Lumbar spine; $(\square)$, femoral neck; $(\square)$, trochanter. The increase in the training group was significantly greater than that of the control group: ${ }^{*} P<0.05$.

age when bone has matured do not experience the same geometric adaptation as that seen in young players ${ }^{(43)}$.

\section{Longitudinal studies}

Although cross-sectional unilateral studies reduce selection bias, they cannot prove that exercise causes an increase in BMD. Moreover, reaching conclusions from observations of different athlete groups is difficult because of baseline differences between individuals in hormone levels and $\mathrm{Ca}$ intake etc., differences in prescription of the exercise training between groups and uncertain assessment of the loading modality of different sports.

The strongest evidence comes from longitudinal intervention studies, particularly randomised controlled trials (RCT). Despite being fewer in number and weaker in treatment effect, reported RCT continue to support the contention that mechanical loading has a beneficial effect on the skeleton. Older sedentary women (60-74 years of age) who were randomly allocated to perform a training programme involving impact activities were shown to increase their femoral-neck BMD by $3.5 \%$ after 11 months, whilst no significant BMD changes were found in the women who undertook non-impact activities or no training at all ${ }^{(44)}$. The findings of another RCT have emphasised that the peak load is more important than the number of loading cycles in increasing bone mass ${ }^{(45)}$. In this trial post-menopausal women were assigned to a 1-year-long resistance-training regimen that prescribed either three sets of eight repetitions or three sets of twenty repetitions and it was concluded that high loads and low repetitions increase BMD to a greater extent than endurance programmes of low loads and many repetitions.

RCT have also supported the evidence from animal and cross-sectional studies that the osteogenic response of bone to loading is age dependent. A 9-month step-aerobic programme produced greater bone gain in exercising premenarcheal girls than in sedentary premenarcheal girls, but not in exercising postmenarcheal girls ${ }^{(46)}$, thereby supporting the hypothesis that young bone has the strongest response to mechanical loading. Nonetheless, it is clear that exercise continues to benefit the skeleton through the other decades of life. The RCT that have examined effects of brief high-impact exercise in premenopausal women have shown positive effects on BMD (Fig. 3), but the capacity of the aged skeleton to adapt to the mechanical stress of exercise seems weaker ${ }^{(47)}$, perhaps because of inadequate oestrogen levels and inadequate dietary $\mathrm{Ca}^{(3)}$. This observation is consistent with findings from animal models and cross-sectional studies. After the menopause mechanical loading may serve more to prevent bone loss than to produce large increases in bone mineral, as some RCT examining the effects of exercise in post-menopausal women have shown that the training group maintains BMD while the control group continues losing the BMD, as would be expected in this population ${ }^{(48)}$. Physical activity and oestrogen therapy have been reported to have additive effects on bone in older post-menopausal women ${ }^{(49)}$, although one study has suggested that brief high-intensity resistance exercise alone is as effective as the combination of exercise and hormone-replacement therapy in early post-menopausal women ${ }^{(50)}$. This discrepancy may be explained by the suggestion that loading influences bone through oestrogen receptor $\alpha^{(51)}$, which is down regulated in the later post-menopausal period. Lesser effects of exercise on bone after menopause may also be explained by the tendency to use lower-intensity interventions in this population, in order to reduce the risk of injury or improve compliance.

A recent meta-analysis of selected RCT that have investigated the effect of exercise on bone mass has revealed positive effects of exercise on the lumbar spine and femoral neck in premenopausal women ${ }^{(52)}$. Based on yearly estimated changes in $\mathrm{BMD}$, the overall treatment effect was found to be 1.5 (95\% CI $0.6,2.4) \%$ at the spine and $0.7(95 \% \mathrm{CI}-0.3,-1.7) \%$ at the femoral neck. Although collectively RCT show that regular exercise can delay or halt bone loss in women (Table 1), the exerciseinduced increases in BMD reported in longitudinal studies are much smaller and less convincing than the results of cross-sectional studies. As described earlier, the lack of consistency between studies is probably caused by the heterogeneity of the trials. The extent of variation relating to the study populations (e.g. pre- or post-menopausal women), the type, length and intensity of the exercise programmes and the duration of the follow-up periods can make meaningful meta-analysis not feasible ${ }^{(53)}$. There are a number of limitations to some of the earlier RCT concerning exercise and bone: (1) the exercise programmes were sometimes too general rather than specific in loading the hip or spine, which were the clinically-important sites measured; (2) considering the physiological limits of bone formation and remodelling, the duration of the protocols was sometimes too short to observe significant effects of a lifestyle intervention like exercise; (3) most studies used BMD as their primary outcome measure, which is a suboptimal surrogate for bone fracture rates; (4) many trials had small sample sizes that are associated with type II error.

Intervention studies that have investigated the effects of exercise training on BMD cover a range of exercise types, 
Table 1. Changes in bone density in exercise relative to control group in published meta-analyses of randomised controlled trials

\begin{tabular}{|c|c|c|c|}
\hline Type of intervention & Group & Site & $\begin{array}{c}\text { Overall treatment effect } \\
\text { ( } \% \text { change in bone mass per year) }\end{array}$ \\
\hline \multirow[t]{3}{*}{ Strength training } & Premenopausal & $\begin{array}{l}\text { LS } \\
\text { FN }\end{array}$ & $\begin{array}{l}0.98^{*}, 1 \cdot 2 \dagger \\
\mathrm{NS}^{*}, \text { not reported } \dagger\end{array}$ \\
\hline & \multirow[t]{2}{*}{ Post-menopausal } & LS & 0.44 (NS) $\ddagger, 1.0 \dagger$ \\
\hline & & $\mathrm{FN}$ & $0.86(\mathrm{NS}) \ddagger^{\prime}, 1.4 \dagger, 0.73(\mathrm{NS}) \S$ \\
\hline \multirow[t]{4}{*}{ Aerobic impact exercise } & \multirow[t]{2}{*}{ Premenopausal } & LS & $1 \cdot 5 \dagger$ \\
\hline & & $\mathrm{FN}$ & $0.9 \dagger$ \\
\hline & \multirow[t]{2}{*}{ Post-menopausal } & LS & $0.96 \ddagger, 1.6 \dagger$ \\
\hline & & FN & $0.9 \ddagger, 0.9 \dagger$ \\
\hline \multirow{4}{*}{$\begin{array}{l}\text { Aerobic exercise combined } \\
\text { with strength training }\end{array}$} & \multirow[t]{2}{*}{ Premenopausal } & LS & $0.91 \ddagger$ \\
\hline & & FN & $0.9 \ddagger$ \\
\hline & \multirow[t]{2}{*}{ Post-menopausal } & LS & $0.79 \ddagger$ \\
\hline & & $\mathrm{FN}$ & $0 \cdot 89 \ddagger$ \\
\hline
\end{tabular}

LS, lumbar spine; FN, femoral neck.

*Martyn-St James \& Carroll ${ }^{(66)}$.

tWallace \& Cumming ${ }^{(52)}$.

†Wolff et al. ${ }^{(67)}$

§Kelley \& Kelley ${ }^{(68)}$

intensities, frequencies and durations, but very few have compared different prescriptions within the same trial, so it is difficult to determine the optimum. This aspect is important because as well as recommending certain types of exercise and how long to exercise for, individuals also need to know how many times per week to exercise. It is clear that there is a need for randomised trials that compare the effects of different exercise prescriptions on bone.

\section{Longitudinal unilateral studies}

Although RCT avoid some of the limitations involved in cross-sectional studies, differences in genetic and environmental determinants of BMD between individuals (e.g. Ca intake, baseline activity level, oestrogen level etc.) may still introduce some variance and, along with some of the previously mentioned weaknesses in design, the training programmes used may not produce the maximum osteogenic response in the skeletal sites being measured. In addition, RCT often struggle to recruit large numbers of participants. Unilateral training programmes overcome some of these limitations, as each participant has their own matched control limb, hence it can be confirmed that any differences between the trained and control limb have been caused by the exercise intervention and not any other factor. Furthermore, the paired design reduces the required sample size.

Very few RCT have used a unilateral study design. Unilateral strength training of the upper $\operatorname{limb}^{(54)}$ or lower $\operatorname{limb}^{(55)}$ does not affect BMD; the lack of exercise effect seen in the premenopausal women may be explained by the low compliance rate reported (56\% and $78 \%$ respectively), loading may have been inadequately different in magnitude and distribution from the habitual loading of the alreadyactive subjects (their $\mathrm{Ca}$ intake was $<800 \mathrm{mg}$ ) and there was no control for menstrual irregularities. On the other hand, a training effect of upper-limb strength training has been observed ${ }^{(45)}$, which may be explained by the high compliance rate of the participants $(82 \%)$ and the likelihood that the exercises were a greater stimulus for the ageing bones of the sedentary women. Thus, if the exercise intervention is designed specifically for the population being examined, a unilateral training programme would serve as a useful way to isolate the effects of mechanical loading on bone.

\section{Defining the optimal exercise prescription for bone health}

If evidence demonstrates that brief rapid-onset highintensity unusually-distributed strains produce a maximal osteogenic response, it follows that low-repetition highimpact jumping would be an ideal type of activity to stimulate bone formation. Jumping is an efficient activity because one jump produces two rapid reversals of strain (take-off and landing), and it is also a feasible activity since its short duration ( $<2$ min for fifty jumps) means that it can be conveniently fitted into daily living. Indeed, jumping has been found to produce GRF and muscle actions that provide large stimuli for bone. Jumping modest heights translate into GRF ranging between 2 and $5 \times$ body weight ${ }^{(47,56)}$, which as demonstrated with implanted hip prostheses are then almost trebled when converted into in vivo compressive forces on the hip ${ }^{(57)}$. Interventions incorporating ten to 100 jumps performed three to seven times weekly increases BMD in young adult women $^{(47,58-61)}$ (Fig. 3), demonstrating that this higherimpact loading elicits the overload necessary to stimulate bone formation.

Considering the strengths of a unilateral exercise design and the previously mentioned effectiveness of a highimpact activity like jumping, it follows that unilateral single-legged jumping in the form of hopping exercises may stimulate an even greater bone response. Hypothetically, GRF values would double if only one leg supported the weight of the whole body, as happens during a hop, as opposed to body weight being distributed on two legs, as is 


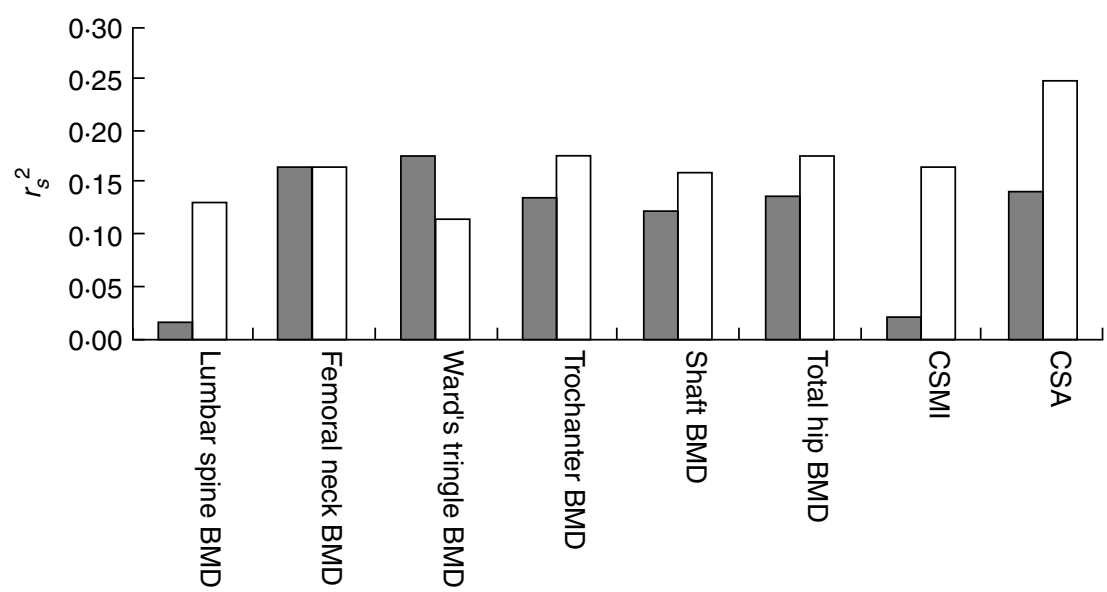

Fig. 4. Proportion of variance $\left(r_{s}^{2}\right)$ in bone variables explained by isometric knee extensor strength $(\square)$ and ground-reaction forces $(\square)$ in sedentary premenopausal women. BMD, bone mineral density; CSMI, cross-sectional moment of inertia; CSA, cross-sectional area. (From Bailey et al. ${ }^{(62)}$ )

(A)

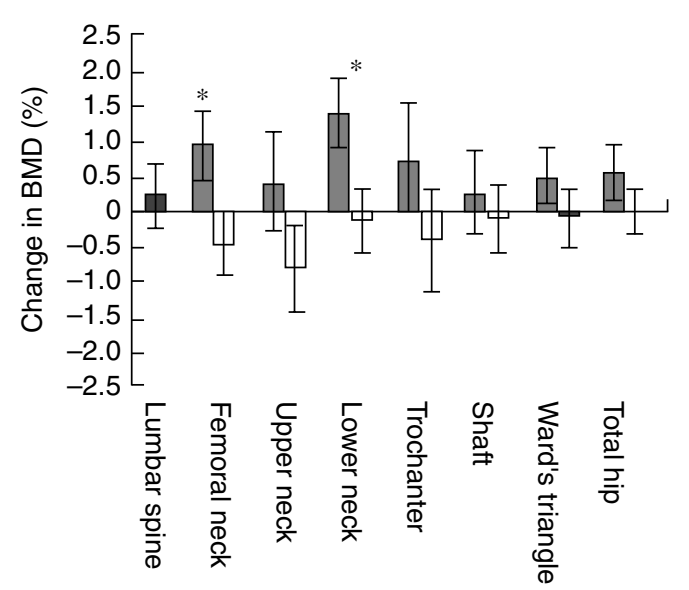

(B)

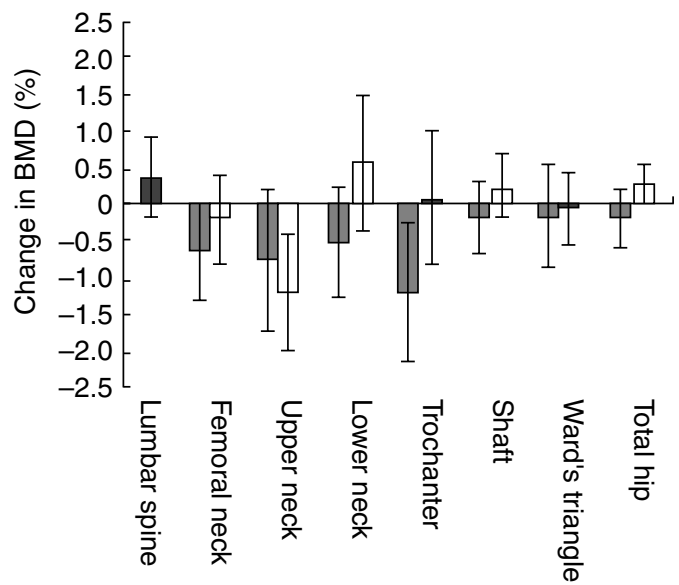

Fig. 5. Changes in bone mineral density (BMD) following a 6-month high-impact unilateral intervention study during which twenty-one sedentary premenopausal women performed an intervention that included fifty multidirectional hops between two and seven times per week $(A)$ and ten controls continued their normal lifestyle (B). $\square$, Lumbar spine; $(\square)$, Trained leg; $(\square)$, control leg. Values are means with their standard errors represented by vertical bars. The difference between legs and between groups was significant: ${ }^{*} P<0 \cdot 05$. (From Bailey et al. ${ }^{(65)}$ )

the case during a jump. An important feature of jumping is that it involves strain distributions on the skeleton that are atypical for women who do not engage in high-impact sports $^{(47)}$, thereby placing unusual but effective mechanical strain on bones. Accordingly, multidirectional hopping exercises may be an even more unusual activity for inactive women, thus having an even greater osteogenic potential on the specific skeletal sites that come under strain.

A series of studies have recently been conducted to assess a programme of multidirectional hopping exercises in terms of GRF, feasibility and overall effectiveness with the aim of using such a high-impact unilateral exercise intervention to study the optimal exercise prescription for healthy premenopausal women. First, it was found that the
GRF acting on one leg during a maximal vertical hop (mean 3.7 (SD 0.4$) \times$ body weight) exceeds the GRF acting on one leg during a maximal jump (mean $2 \cdot 1$ (SD $0 \cdot 4) \times$ body weight per leg, assuming symmetrical distribution of body weight on each foot $)^{(62)}$. Despite a lower hop height (mean 132 (SD 18) $\mathrm{mm}$ for a hop $v$. mean 241 (SD 46) mm for a jump), the GRF values recorded were found to be greater than those measured previously in a study that reported an increase in BMD at the trochanter following a jumping programme ${ }^{(47)}$. These comparisons indicate that hopping generates sufficient GRF to potentially provoke gains in BMD. Cross-sectional analyses of subsequent baseline data support this conclusion by demonstrating positive associations between GRF and bone indices, in most cases more than muscular strength (Fig. 4). 
Second, a pilot study has indicated that performing an intervention including a warm-up and hopping exercises in the long term would be feasible, as evidenced by $99 \%$ compliance with a 6-week-long intervention (CA Bailey and $\mathrm{K}$ Brooke-Wavell, unpublished results). Importantly, no injuries were sustained and only one of the twelve participants experienced muscle soreness, which was short lived. The high compliance rate may be a result of the low demands of the programme, because unlike many exercise studies the participants were not required to spend time travelling to a specific location to perform the training in a group under supervision ${ }^{(63,64)}$. Instead they were free to decide where and when to do their hopping exercises, thereby making it a much easier task to fit into their daily routine.

Last, in terms of the effectiveness of hopping to increase $\mathrm{BMD}$, the results of a 6-month-long intervention study, during which twenty-one sedentary premenopausal women performed an intervention that included fifty multidirectional hops between two and seven times per week, show that BMD at the femoral neck and lower neck of the hoppers' trained leg is increased by $1.04 \%(P=0.041)$ and $0.9 \%(P=0.048)$ respectively in comparison with their control leg ${ }^{(65)}$ (Fig. 5). The ten controls, who continued their normal lifestyle, were not found to show changes in BMD at either site. As well as positive changes in BMD, changes were also found in hop height, muscle strength and balance, all factors that contribute to reduced falls and subsequent fractures. Thus, brief hopping exercises could have positive local effects on sites that are important in osteoporosis prevention.

\section{Conclusions and implications}

Physical activity has been shown to reduce skeletal fragility and predisposition to falls through a combination of increased BMD and improved physical capabilities such as coordination, balance, reaction time and muscle function. In the human model the determination of a dose-response relationship is hindered by a lack of the appropriate technology to directly evaluate mechanical loading and skeletal competence. However, results from both animal and human trials indicate that if strains are high in magnitude, rapidly-applied, dynamic and novel a considerable bone response can be achieved at the skeletal site coming under strain with remarkably short durations of loading. Prescribing a specific and efficient exercise programme for optimum bone health could therefore be based on these principles so that each individual maximises benefits from their time and effort spent on exercise. The issue of feasibility and practicality is paramount not only for adherence to research interventions but also to lifestyle intervention. The optimal exercise prescription still needs further definition. Moreover, more research among non-athletic premenopausal women, who are a more accurate reflection of the general population, is needed. High-impact unilateral exercise interventions may provide a useful method of assessing the relationship between mechanical loading and bone to more precisely define the most advantageous exercise prescription for optimising peak bone mass.

\section{References}

1. van Staa TP, Dennison EM, Leufkens HGM \& Cooper C (2001) Epidemiology of fractures in England and Wales. Bone 29, 517-522.

2. Torgerson DJ \& Dolan P (2000) The cost of treating osteoporotic fractures in the United Kingdom female populationThe author replies. Osteoporos Int 11, 551-552.

3. Borer KT (2005) Physical activity in the prevention and amelioration of osteoporosis in women: interaction of mechanical, hormonal and dietary factors. Sports Med 35, 779-830.

4. Kohrt WM, Bloomfield SA, Little KD, Nelson ME \& Yingling VR (2004) Physical activity and bone health. Med Sci Sports Exerc 36, 1985-1996.

5. Pollock ML, Gaesser GA, Butcher JD et al. (1998) ACSM Position Stand: The recommended quantity and quality of exercise for developing and maintaining cardiorespiratory and muscular fitness, and flexibility in healthy adults. Med Sci Sports Exerc 30, 975-991.

6. Beck BR \& Snow CM (2003) Bone health across the lifespan - exercising our options. Exerc Sport Sci Rev 31, 117 122.

7. Frost HM (1987) The mechanostat: a proposed pathogenic mechanism of osteoporosis and the bone mass effects of mechanical and non-mechanical agents. J Bone Miner Res $\mathbf{2}$, 73-85.

8. Skerry TM (2006) One mechanostat or many? Modifications of the site-specific response of bone to mechanical loading by nature and nurture. J Musculoskelet Neuron Interact $\mathbf{6}$, $122-127$.

9. Lanyon LE (1996) Using functional loading to influence bone mass and architecture: objectives, mechanisms, and relationship with estrogen of the mechanically adaptive process in bone. Bone 18, S37-S43.

10. Shackelford LC, LeBlanc AD, Driscoll TB et al. (2004) Resistance exercise as a countermeasure to disuse-induced bone loss. J Appl Physiol 97, 119-129.

11. LeBlanc A, Schneider V \& Shackelford L (2000) Bone mineral and lean tissue loss after long duration space flight. J Musculoskelet Neuron Interact 1, 157-160.

12. Watts NB (2004) Fundamentals and pitfalls of bone densitometry using dual-energy X-ray absorptiometry (DXA). Osteoporos Int 15, 847-854.

13. Kaptoge S, Dalzell N, Jakes RW et al. (2003) Hip section modulus, a measure of bending resistance, is more strongly related to reported physical activity than BMD. Osteoporos Int 14, 941-949.

14. Petit MA, McKay HA, MacKelvie KJ, Heinonen A, Khan KM \& Beck TJ (2002) A randomized school-based jumping intervention confers site and maturity-specific benefits on bone structural properties in girls: a Hip Structural Analysis study. J Bone Miner Res 17, 363-372.

15. Adami S, Gatti D, Braga V, Bianchini D \& Rossini M (1999) Site-specific effects of strength training on bone structure and geometry of ultradistal radius in postmenopausal women. J Bone Miner Res 14, 120-124.

16. Järvinen TLN, Kannus P \& Sievanen H (1999) Have the DXA-based exercise studies seriously underestimated the effects of mechanical loading on bone? J Bone Miner Res 14, 1634-1635.

17. Lanyon LE (1987) Functional strain in bone tissue as an objective, and controlling stimulus for adaptive bone remodelling. J Biomech 20, 1083-1093.

18. Rubin CT \& Lanyon LE (1985) Regulation of bone mass by mechanical strain magnitude. Calcif Tissue Int 37, 411-417. 
19. Mosley JR \& Lanyon LE (1998) Strain rate as a controlling influence on adaptive modeling in response to dynamic loading of the ulna in growing male rats. Bone 23, 313-318.

20. Turner $\mathrm{CH} \&$ Robling AG (2005) Mechanisms by which exercise improves bone strength. J Bone Miner Metab 23, $16-22$.

21. Umemura $\mathrm{Y}$, Ishiko $\mathrm{T}$, Yamauchi $\mathrm{T}$, Kurono $\mathrm{M} \&$ Mashiko $\mathrm{S}$ (1997) Five jumps per day increase bone mass and breaking force in rats. J Bone Miner Res 12, 1480-1485.

22. Srinivasan S, Weimer DA, Agans SC, Bain SD \& Gross TS (2002) Low-magnitude mechanical loading becomes osteogenic when rest is inserted between each load cycle. J Bone Miner Res 17, 1613-1620.

23. LaMothe JM \& Zernicke RF (2004) Rest insertion combined with high-frequency loading enhances osteogenesis. J Appl Phys 96, 1788-1793.

24. Robling AG, Burr DB \& Turner CH (2001) Recovery periods restore mechanosensitivity to dynamically loaded bone. J Exp Biol 204, 3389-3399.

25. Rubin CT, Bain SD \& McLeod KJ (1992) Suppression of the osteogenic response in the aging skeleton. Calcif Tissue Int 50, 306-313

26. Flieger J, Karachalios T, Khaldi L, Raptou P \& Lyritis G (1998) Mechanical stimulation in the form of vibration prevents postmenopausal bone loss in ovariectomized rats. Calcif Tissue Int 63, 510-514.

27. Peng Z, Tuukkanen J \& Vaananen HK (1994) Exercise can provide protection against bone loss and prevent the decrease in mechanical strength of femoral neck in ovariectomized rats. J Bone Miner Res 9, 1559-1564.

28. Heinonen A, Kannus P, Sievanen H, Haapasalo H, Manttari A \& Vuori I (1995) Bone mineral density in female athletes representing sports with different loading characteristics of the skeleton. Bone 17, 197-203.

29. Nikander R, Sievanen H, Heinonen A \& Kannus P (2005) Femoral neck structure in adult female athletes subjected to different loading modalities. J Bone Miner Res 20, 520528.

30. Pettersson U, Nordstrom P, Alfredson H, Henriksson-Larsen K \& Lorentzon R (2000) Effect of high impact activity on bone mass and size in adolescent females: a comparative study between two different types of sports. Calcif Tissue Int 67, 207-214.

31. Robinson TL, Snow-Harter C, Taaffe DR, Gillis D, Shaw J \& Marcus R (1995) Gymnasts exhibit higher bone mass than runners despite similar prevalence of amenorrhea and oligomenorrhea. J Bone Miner Res 10, 26-35.

32. McNitt-Gray JL (1993) Kinetics of the lower extremities during drop landings from three heights. J Biomech 26, 1037-1046.

33. Duncan CS, Blimkie CJR, Cowell CT, Burke ST, Briody JN \& Howman-Giles R (2002) Bone mineral density in adolescent female athletes: relationship to exercise type and muscle strength. Med Sci Sports Exerc 34, 286-294.

34. Milgrom C, Miligram M, Simkin A, Burr D, Ekenman I \& Finestone A (2001) A home exercise program for tibial bone strengthening based on in vivo strain measurements. Am J Phys Med Rehabil 80, 433-438.

35. Snow CM (1996) Exercise and bone mass in young and premenopausal women. Bone 18, S51-S55.

36. Drinkwater BL (1994) C. H. McCloy Research Lecture: Does physical activity play a role in preventing osteoporosis? Res Q Exerc Sport 65, 197-206.

37. Heikkinen R, Vihriala E, Vainionpaa A, Korpelainen R \& Jamsa $T$ (2006) Association between the strain rate of exercise-induced impacts and changes in bone density. J Biomech 39, 22.
38. Nelson DA \& Bouxsein ML (2001) Exercise maintains bone mass, but do people maintain exercise? J Bone Miner Res 16, 202-204.

39. Chilibeck PD, Davison KS, Sale DG, Webber CE \& Faulkner RA (2000) Effect of physical activity on bone mineral density assessed by limb dominance across the lifespan. Am J Hum Biol 12, 633-637.

40. MacIntyre NJ, Adachi JD \& Webber CE (1999) In vivo detection of structural differences between dominant and nondominant radii using peripheral quantitative computed tomography. J Clin Densitom 2, 413-422.

41. Kannus P, Haapasalo H, Sievanen H, Oja P \& Vuori I (1994) The site-specific effects of long-term unilateral activity on bone mineral density and content. Bone 15, 279 284.

42. Hääpasalo H, Kannus P, Sievanen H et al. (1998) Effect of long-term unilateral activity on bone mineral density of female junior tennis players. J Bone Miner Res 13, 310-319.

43. Nara-Ashizawa N, Liu LJ, Higuchi T et al. (2002) Paradoxical adaptation of mature radius to unilateral use in tennis playing. Bone 30, 619-623.

44. Kohrt WM, Ehsani AA \& Birge SJJ (1997) Effects of exercise involving predominantly either joint-reaction or ground-reaction forces on bone mineral density in older women. J Bone Miner Res 12, 1253-1261.

45. Kerr D, Morton A, Dick I \& Prince R (1996) Exercise effects on bone mass in postmenopausal women are site-specific and load-dependent. J Bone Miner Res 11, 218-225.

46. Heinonen A, Sievänen H, Kannus P, Oja P, Pasanen M \& Vuori I (2001) High-impact exercise and bones of growing girls: a 9-month controlled trial. Osteoporos Int 11, 10101017.

47. Bassey EJ, Rothwell MC, Littlewood JJ \& Pye DW (1998) Pre- and postmenopausal women have different bone mineral density responses to the same high-impact exercise. $J$ Bone Miner Res 13, 1805-1813.

48. Engelke K, Kemmler W, Lauber D, Beeskow C, Pintag R \& Kalender WA (2006) Exercise maintains bone density at spine and hip EFOPS: a 3-year longitudinal study in early postmenopausal women. Osteoporos Int 17, 133-142.

49. Kohrt WM, Snead DB, Slatopolsky E \& Birge SJ (1995) Additive effects of weight-bearing exercise and estrogen on bone mineral density in older women. J Bone Miner Res $\mathbf{1 0}$, 1303-1311.

50. Maddalozzo GF, Widrick JJ, Cardinal BJ, Winters-Stone KM, Hoffman MA \& Snow CM (2007) The effects of hormone replacement therapy and resistance training on spine bone mineral density in early postmenopausal women. Bone 40, 1244-1251.

51. Lee KCL \& Lanyon LE (2004) Mechanical loading influences bone mass through estrogen receptor alpha. Med Sci Sports Exerc 32, 64-68.

52. Wallace BA \& Cumming RG (2000) Systematic review of randomized trials of the effect of exercise on bone mass in pre- and postmenopausal women. Calcif Tissue Int 67, $10-18$.

53. Ernst E (1998) Exercise for female osteoporosis: a systematic review of randomised clinical trials. Sports Med 25, 359-368.

54. Heinonen A, Sievanen H, Kannus P, Oja P \& Vuori I (1996) Effects of unilateral strength training and detraining on bone mineral mass and estimated mechanical characteristics of the upper limb bones in young women. J Bone Miner Res 11, 490-501.

55. Vuori I, Heinonen A, Sievanen H, Kannus P, Pasanen M \& Oja P (1994) Effects of unilateral strength training and detraining on bone mineral density and content in young 
women - a study of mechanical loading and deloading on human bones. Calcif Tissue Int 55, 59-67.

56. McKay H, Tsang G, Heinonen A, MacKelvie K, Sanderson D \& Khan KM (2005) Ground reaction forces associated with an effective elementary school based jumping intervention. Br J Sports Med 39, 10-14.

57. Bassey EJ, Littlewood JJ \& Taylor SJG (1997) Relations between compressive axial forces in an instrumented massive femoral implant, ground reaction forces, and integrated electromyographs from vastus lateralis during various 'osteogenic' exercises. J Biomech 30, 213-223.

58. Bassey EJ \& Ramsdale SJ (1994) Increase in femoral bone density in young women following high-impact exercise. Osteoporos Int 4, 72-75.

59. Kato T, Terashima T, Yamashita T, Hatanaka Y, Honda A \& Umemura Y (2006) Effect of low-repetition jump training on bone mineral density in young women. J Appl Physiol 100, 839-843.

60. Vainionpaa A, Korpelainen R, Leppaluoto J \& Jamsa T (2005) Effects of high-impact exercise on bone mineral density: a randomized controlled trial in premenopausal women. Osteoporos Int 16, 191-197.

61. Winters-Stone KM \& Snow CM (2006) Site-specific response of bone to exercise in premenopausal women. Bone 39, 1203-1209.

62. Bailey CA, Parsons A \& Brooke-Wavell K (2007) Does muscle function predict bone mineral density and proximal femoral geometry in sedentary premenopausal women? Osteoporos Int 18 (Suppl. 3), S276.

63. Friedlander AL, Genant HK, Sadowsky S, Byl NN \& Gluer CC (1995) A two-year program of aerobics and weight training enhances bone mineral density of young women. $J$ Bone Miner Res 10, 574-585.

64. Heinonen A, Oja P, Sievanen H, Pasanen M \& Vuori I (1998) Effect of two training regimens on bone mineral density in healthy perimenopausal women: a randomized controlled trial. J Bone Miner Res 13, 483-490.

65. Bailey CA, Parsons A \& Brooke-Wavell K (2007) Brief unilateral hopping exercises increase femoral neck bone mineral density in the trained leg of sedentary premenopausal women. Osteoporos Int 18 (Suppl. 3), S285.

66. Martyn-St James M \& Carroll S (2006) Progressive high-intensity resistance training and bone mineral density changes among premenopausal women: evidence of discordant site-specific skeletal effects. Sports Med 36, 683704.

67. Wolff I, van Croonenborg JJ, Kemper HCG, Kostense PJ, Twisk JWR (1999) The effect of exercise training programs on bone mass: A meta-analysis of published controlled trials in pre- and postmenopausal women. Osteoporos Int 9, 1-12.

68. Kelley GA \& Kelley KS (2006) Exercise and bone mineral density at the femoral neck in postmenopausal women: A meta-analysis of controlled clinical trials with individual patient data. Am J Obstet Gynecol 194, 760-767. 